\title{
Sosialisasi Computational Thinking Mata Pelajaran Bahasa Inggris untuk Guru-Guru MI dan MTs Wilayah Lombok Tengah
}

\author{
Diah Supatmiwati ${ }^{1}$, Wiya Suktiningsih ${ }^{2}$, Anthony Anggrawan ${ }^{3}$, Katarina ${ }^{4}$ \\ diah.supatmiwati@universitasbumigora.ac.id ${ }^{1}$, \\ wiya.suktiningsih@universitasbumigora.ac.id², \\ anthony.anggrawan@universitasbumigora.ac.id ${ }^{3}$, katarina@universitasbumigora.ac.id ${ }^{4}$ \\ 1,2,3,4 Universitas Bumigora
}

\section{Article History:}

Received: 11-06-2021

Revised : 29-06-2021

Accepted: 22-07-2021

\begin{abstract}
Computational thinking (CT) or in Indonesian called computational thinking is a method to train thinking skills in solving problems with reasoning and analysis, initially computational thinking is always related to computers. In fact, computational computing does not teach how to use computers or things that are always related to but the thought processes used to support problem science in all disciplines, mathematics, science, social studies, and languages, in this case the socialization of CT in learning English and Indonesian. Computational thinking can teach from an early age, starting from the elementary school level (SD) or the equivalent (MI) by making questions in English and Indonesian subjects by providing examples of simple problem solving found in basic language lessons. Through this community service, you can socialize CT to MI and MTs secondary school teachers in Central Lombok, the content is so that teachers can enter or enter CT into the subject they are taught, so that students are familiar with problems solving problems by means of computational thinking, the sustainable survival of computational thinking, a problem can be resolved properly, quickly and optimally.
\end{abstract}

Keywords: $\quad$ Computational
thinking: MI; MTs; socialization; teachers

\section{Pendahuluan}

Computational Thinking (CT) adalah sebuah pendekatan baru dalam proses pembelajaran yang bisa disandingkan dengan metode pembelajaran yang sudah ada. Pemanfaatan teknologi juga diharapkan dapat meningkatkan pemahaman dan penggunaan sebagai sarana pembelajaran(Bebras 2018). Awalnya CT berperan dalam pengembangan aplikasi komputer, kemudian $C T$ juga dapat digunakan untuk mendukung pemecahan masalah disemua disiplin ilmu, termasuk humaniora, matematika dan ilmu pengetahuan.

Dalam penerapannya di kurikulum (proses pembelajaran) siswa dapat melihat hubungan antara mata pelajaran, serta antara kehidupan di dalam dengan di luar kelas Berpikir komputasi adalah teknik pemecahan masalah yang bisa diterapkan pada berbagai bidang ilmu. Tidak mengherankan bahwa memiliki kemampuan tersebut adalah sebuah keharusan bagi seseorang yang hidup pada abad ke dua puluh satu. Seperti juga bermain https://journal.universitasbumigora.ac.id/index.php/ADMA 
musik dan belajar bahasa asing, CT melatih otak untuk terbiasa berfikir secara logis, terstruktur dan kreatif. Pendekatan berfikir Komputasi, CT merupakan pendekatan untuk pemecahan masalah yang melibatkan penggunaan serangkaian praktik dan prinsip dari ilmu komputer untuk merumuskan solusi yang dapat dieksekusi oleh komputer. CT juga bisa diterapkan dibidang lain, salah satunya adalah bidang pelajaran bahasa Inggris dan Bahasa Indonesia. Metode pembelajaran bahasa dengan metode ini menjadi lebih praktis dan menyenangkan bagi siswa madrasah Ibtidaiyah dan madrasah Tsanawiyah(Rozi 2020). Dengan metode pedekatan ini diharapkan stigma sulitnya belajar Bahasa dapat dihilangkan. Pendekatan ini diharapkan mampu meningkatkan keterampilan berfikir secara kritis dan kreatif para siswa serta memberikan dasar untuk menyiapkan generasi penerus yang berdaya saing di era Revolusi Industri 4.0(Diy 2021).

Jeanette Wing (2016) memperkenalkan kembali istilah Computational thinking pada Maret 2006, Wing mengkatagorikan CT penyelesaian masalah, merancang system dan memahami perilaku manusia dengan mengambarkan konsep dasar kedalam computer science (Wing 2008). Pada tahun 2011, Jeannette memperkenalkan definisi baru, yang mana: computational thinking adalah proses berpikir yang diperlukan dalam memformulasikan masalah dan solusinya, sehingga solusi tersebut dapat menjadi agen pemroses informasi yang efektif dalam menyelesaikan masalah.

Dua aspek dari definisi tersebut adalah :

1) Computational thinking adalah sebuah proses pemikiran, yang terlepas dari teknologi.

2) Computational thinking adalah metode penyelesaian masaah yang dirancang untuk dapat selesaikan dan dijalankan oleh manusia, komputer atau kedua-duanya.

Dalam perkembangannya computational thinking tidak lagi selalu berkaitan dengan komputer, namun berubah menjadi suatu metode atau cara berpikir yang bias disisipkan pada semua mata pelajaran. siswa-siswa perlu mendapatkan kemampuan yang tidak hanya terkait dengan membaca, menulis, dan aritmatika, mereka perlu dibekali dengan kemampuan berpikir logis dalam pemecahan masalah. Menurut Korkmaz et al. (2017), CT merupakan perluasan dari keterampilan pemecahan masalah seseorang dan pengembangan kreativitas dan keterampilan berpikir kritis dengan cara meningkatkan kreativitas, kreativitas memainkan peran penting dalam pendekatan CT (Yadav, Hong, and Stephenson 2016).

Bebras adalah sebuah forum internasional yang tujuannya adalah untuk mempromosikan computational thinking, di kalangan guru dan murid mulai kelas 3 sekolah dasar (SD), serta untuk masyarakat luas (Bebras 2017). Secara harfiah, "Bebras" adalah kata dalam bahasa Lithuania, yang berarti "berang-berang" dalam bahasa Indonesia. Prof. Valentina Dagiene dari Universitas Vilnius, Lithuania adalah tokoh yang mencetuskan 
gagasan Bebras Challenge, yang saat ini diikuti oleh kurang lebih 50 negara di dunia. Komunitas ini mengenal dan mengajarkan berpikir komputasi dengan beberapa contoh permasalahan yang disebut tantangan bebras. Tantangan bebras menyajikan soal-soal yang mendorong siswa untuk berpikir kreatif dan kritis dalam menyelesaikan persoalan dengan menerapkan konsep-konsep berpikir komputasional.

Menyadari pentingnya konsep berpikir komputasil untuk kalangan guru dan siswa sekolah, sejak tahun 2005, komunitas Bebras internasional (bebras.org) ini menggelar Tantangan Bebras (Bebras Challenge) secara berkala untuk mengedukasi konsep berpikir komputasional dan informatika kepada siswa sekolah pada berbagai tingkatan usia. Siswa yang mengikuti kompetisi Bebras biasanya dibimbing oleh guru dalam persiapan sebelumnya. Kompetisi dilaksanakan dalam jaringan (online) melalui komputer atau gawai pintar.

Kegiatan kompetisi ini dilaksanakan secara nasional oleh komunitas Bebras yang ada di negara yang bersangkutan. Setiap tahun, Bebras Internasional akan mengadakan workshop yang dihadiri oleh wakil komunitas Bebras dari setiap negara yang tergabung dalam komunitas Bebras, laman resmi Bebras Indonesia adalah bebras.or.id. Setiap soal Bebras mengandung aspek komputasi atau informatika dan dimaksudkan untuk menguji bakat peserta untuk berpikir komputasi atau informatika. Untuk menjawab soal-soal Bebras, secara alamiah, siswa dituntut untuk berpikir komputasi serta harus menggunakan konsep analisa algoritma yang biasa digunakan dalam pemograman (Bebras 2018). Dalam menghadapi Bebras Challenge, biro Bebras Universitas Bumigora melakukan sosialisasi CT di wilayah Lombok untuk memepersiapkan siswa-siswa setingkat sekolah dasar dan menengah untuk mengikuti lomba tersebut.

Sosialisasi pertama dilaksanakan di Madrasah ibtidaiyah (MI) setingkat sekolah dasar dan madrasah tsanawiyah setingkat sekolah menengah (MTs) yang dikelola yayasan swasta di wilayah Lombok Tengah. Lombok Tengah dipilih karena kesiapan mitra dalam pelaksanaan kegiatan. Dari koordinasi dengan pihak Yayasan Islamic Studies Iltihadul Ikhlas Aik Mual jumlah peserta yang ikut sosialisasi berasal dari sejumlah MI dan MTs swasta diwilayah Lombok tengah. Menurut data awal yang berhasil dikumpulkan mitra Yayasan Islamic Studies Iltihadul Ikhlas Aik Mual, MI dan MTs yang berminat mengikuti sosialisasi terdiri dari $6 \mathrm{MI}$ dan 22 MTs yang dikelola yayasan swasta yang berada di wilayah Lombok Tengah. Pada kegiatan ini dipaparkan materi tentang computational Thinking yang disampaikan oleh perwakilan Biro Bebras unit Universitas Bumigora Mataram. Kegiatan akan dipusatkan di aula Mts Darul Aminin NW Aik Mual di Jalan Praya Mantang KM7 desa Aik Mual kecamatan Praya, Lombok Tengah. Jumlah guru yang menjadi peserta dirangkum dalam tabel berikut ini: 
Tabel 1. Daftar MI Peserta Sosialisasi Computational Thinking 3 September 2020

\begin{tabular}{|c|l|c|}
\hline No & \multicolumn{1}{|c|}{ Nama Sekolah SD/MI } & Jumlah Guru \\
\hline 1 & Mi Nurul ljtihad Al Ma'arif NU Lenser Kuta & 1 \\
\hline 2 & Mi Darul Abror Nw Rangkep Kuta & 8 \\
\hline 3 & Mis Darul Hikmah Darek & 5 \\
\hline 4 & Mi Nurul Iman Nw Pengembur & 2 \\
\hline 5 & Mi Raudlatul Jannah NW Perempung & 3 \\
\hline 6 & Itihadul Ikhlas & 1 \\
\hline \multicolumn{2}{|c|}{ Jumlah } & $\mathbf{2 0}$ \\
\hline
\end{tabular}

Tabel 2. Daftar MTs Peserta Sosialisasi Computational Thinking 3 September 2020

\begin{tabular}{|c|l|c|}
\hline No & \multicolumn{1}{|c|}{ Nama Sekolah SMP/Mts } & Jumlah Guru \\
\hline 1 & Mas Manhalul Ulum Praya & 1 \\
\hline 2 & Kb Rusyidah Al Ibrahimy Nw & 1 \\
\hline 3 & Mtss Sa Darul Abror & 7 \\
\hline 4 & Mts Darul Aminin Nw Aikmual & 6 \\
\hline 5 & Mtss Darul Hikmah Darek & 4 \\
\hline 6 & Mts Darul Masakin Karang Lebah & 3 \\
\hline 7 & Mts Manhalul Ulum Praya & 5 \\
\hline 8 & Mts Miftahul Ali & 6 \\
\hline 9 & Mts Miftahul Iman Nw Bundua & 1 \\
\hline 10 & Mtss Nurul ljtihad Nu Lenser & 1 \\
\hline 11 & Mtss NURUL IMAN NW KERUAK & 3 \\
\hline 12 & Mts Nurul Yaqin Praya & 4 \\
\hline 13 & Mtss Nurul Iman Nw Pengembur & 2 \\
\hline 14 & Mts Nw Sanggeng & 2 \\
\hline 15 & Mts Raudlatul Jannah Nw Perempung & 2 \\
\hline 16 & Mts Sa'adatuddarain Wakan & 8 \\
\hline 17 & Mts Ulil Absor Panti Jago & 4 \\
\hline 18 & Mts Nurul ljtihad Al Ma'arif Nu Lenser Kuta & 1 \\
\hline 19 & Mts Raudlatul Jannah Nw Perempung & 1 \\
\hline 20 & Mts Manhalul Ulum Praya & 1 \\
\hline 21 & Smp Islam Minhajussalam Nw Manggong & 2 \\
\hline 22 & Smp Islam Rusydah Nw Sengkol & 2 \\
\hline & & 67 \\
\hline
\end{tabular}

Penggunaan computational thinking pada kurikulum 2013 bukan untuk mempelajari kemampuan komputer, namun menjadi materi yang multi disiplin atau bisa masuk ke muatan pelajaran manapun, karena berbentuk soal-soal logika dan analisa algoritma, juga dapat dimasukkan ke bab atau contoh soal manapun dalam suatu pelajaran. Tujuan kegiatan pengabdian kepada masyarakat tentang menyisipkan CT untuk mendukung pemecahan masalah di semua disiplin ilmu, termasuk humaniora, matematika dan ilmu pengetahuan. Siswa yang belajar dimana CT diterapkan dalam kurikulum (proses pembelajaran) dapat mulai melihat hubungan antara mata pelajaran, serta antara kehidupan di dalam dengan di luar kelas. Mata pelajaran Bahasa Inggris dipilih sebagai mata pelajaran 
yang akan disisipkan dengan metode CT. Hal tersebut dikarena bahwa bahasa Inggris sebagai Sebagai bahasa Internasional, Bahasa Inggris banyak digunakan sebagai bahasa penghubung antar negara di dunia dan sarana berkomunikasi secara global(Miranti, Nurjanah, and Dwiastuty 2020). Diharapkan dengan penerapan CT dapat meningkatkan kemampuan berbahasa Inggris sejak dini.

Computational thinking perlu dikenalkan sejak dini, mulai dari tingkat sekolah dasar (SD) melalui para guru yang menyisipkan CT pada materi pelajaran, dengan memberikan contoh soal sederhana serta penyelesaiannya yang terjadi dalam kegiatan sehari-hari. Dengan menyisipkan berpikir komputasi ke dalam dunia pendidikan, dapat melatih dan membiasakan siswa menyelesaikan suatu masalah secara cepat dan terpola, keberhasilan siswa dalam menangani suatu masalah dapat meningkatkan kepercayaan diri siswa itu sendiri. Berdasarkan hasil kuesioner sebelum pengabdian, diketahui para guru belum mengenal berpikir komputasi (computational thinking) baik dari contoh soal ataupun mengimplementasikan ke mata pelajaran masing-masing. Melalui pengabdian ini, mitra yang merupakan guru-guru MI dan MTs swasta wilayah Lombok Tengah diberikan sosialisasi mengenai berpikir komputasi dengan tujuan guru mendapat pemahaman lebih banyak dan dapat menambahkan materi berpikir komputasi pada mata pelajaran di sekolah.

\section{METODE}

Agar tercapai perbaikan atau solusi dari masalah mitra di atas, maka dalam kegiatan pengabdian kepada masyarakat ini dilaksanakan dengan metode, sebagai berikut:
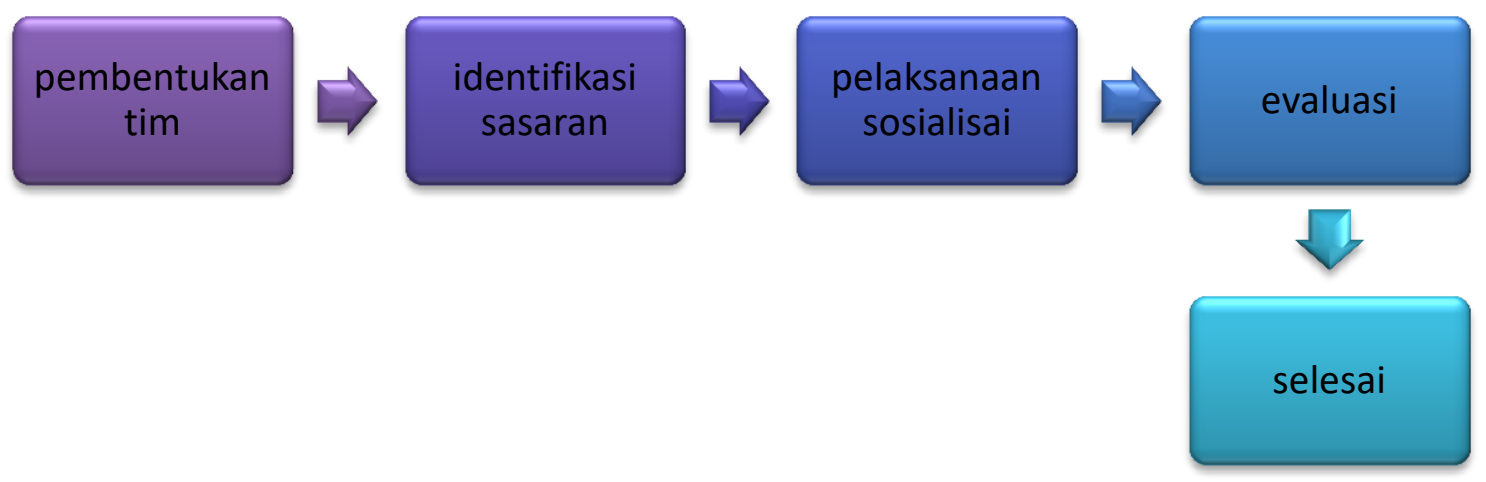

\section{1) Ceramah}

Gambar 1. Metode pelaksanaan

Melalui metode ini disampaikan tentang Computational Thinking (berpikir komputasi) secara umum seperti pengertian, kendala, tantangan dan perkembangannya pada revolusi industri 4.0; kemudian disampaikan juga secara khusus penggunaan materi berpikir komputasi tingkat Sekolah Dasar beserta contoh-contoh laman internet (website) yang dapat digunakan anak-anak untuk belajar komputasi dasar seperti code.org, bebras.or.id dan wolframalpha.com. 


\section{2) Praktik pembahasan contoh soal}

Metode ini diadakan setelah guru-guru menerima teori dari metode ceramah, para guru langsung disajikan contoh soal dan pembahasan Computational Thinking yang dapat digunakan untuk mendorong siswa untuk berpikir kreatif dan kritis dalam menyelesaikan persoalan sehari-hari. Pada sesi ini guru-guru akan didampingi langsung oleh tim dan mahasiswa yang dilibatkan dalam pengabdian ini (Kotsopoulos et al. 2017).

\section{3) Diskusi}

Dengan metode ini peserta dapat langsung bertanya dan berdiskusi kepada tim pengabdian pada masyarakat yang mendampingi mereka selama kegiatan berlangsung. Selanjutnya untuk pengumpulan data dengan menggunakan kuesioner yang dibagi menjadi dua bagian yaitu kuesioner pra pengabdian dan kuesioner pasca pengabdian.

\section{4) Evaluasi}

Agar dapat mengetahui gambaran keberhasilan pengabdian ini dan perbaikan untuk pengabdian kepada masyarakat berikutnya maka dilakukan evaluasi dengan memberikan peserta pertanyaan-pertanyaan berbentuk kuesioner sebelum dan sesudah pelaksanaan pengabdian.

\section{Pembahasan}

Pelaksanaan pengabdian kepada masyarakat ini terlaksana pada hari Sabtu tanggal 5 September 2020 kegiatan dimulai dari dari pukul 08.00 WITA sampai dengan 13.00 WITA dan dihadiri oleh 87 orang peserta yang merupakan guru dari berbagai mata pelajaran di $\mathrm{Ml}$ dan MTS Swasta di wilayah Lombok Tengah. Pada awal kegiatan dibagikan kuesioner prakegiatan, dua pertanyaan utama dalam kuesioner tersebut adalah tentang apakah sudah mengenal CT dan kalau sudah apakah menerapkan CT dalam mata pelajaran yang diampu, dengan hasil sebagai berikut:

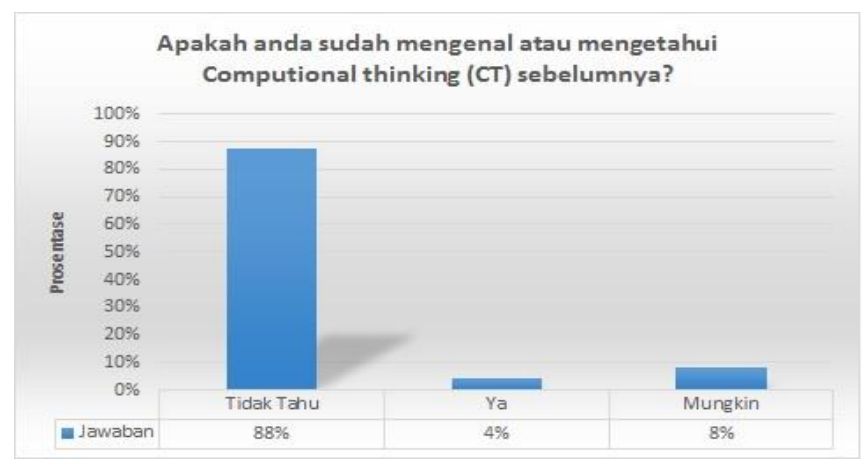

Gambar 2. Hasil dari kuesioner pra-kegiatan 


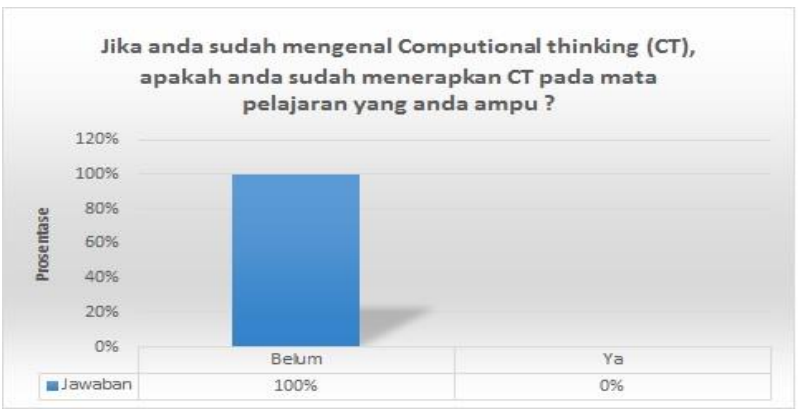

Gambar 3. Penerapan CT pada Mapel Pasca Sosialisasi

Grafik pada gambar 3 menyatakan bahwa 4\% guru yang mengenal computational thinking, semuanya menjawab belum penah menerapkan computational thinking dalam mata pelajarannya. Ditinjau dari sumber daya yang ada, rata-rata guru telah mempunyai laptop sendiri atau telepon pintar yang dapat digunakan untuk mendukung penerapan computational thinking dalam mata pelajaran. Kesimpulannya dari sumber daya dan kemampuan guru seharusnya dapat menerapkan materi computational thinking saat mengajar, namun karena banyak guru yang belum mengenal sehingga belum dapat menerapkannya. Untuk itu sosialisasi ini sesuai dengan target mitra agar dapat mengenal lebih dalam tentang berpikir komputasi.

Kegiatan dilanjutkan dengan pemaparan materi berpikir komputasi oleh tim pengabdian. Pemaparan pertama tentang apa dan bagaimana cara berpikir komputasi yang disampaikan oleh Kartarina Agustin.

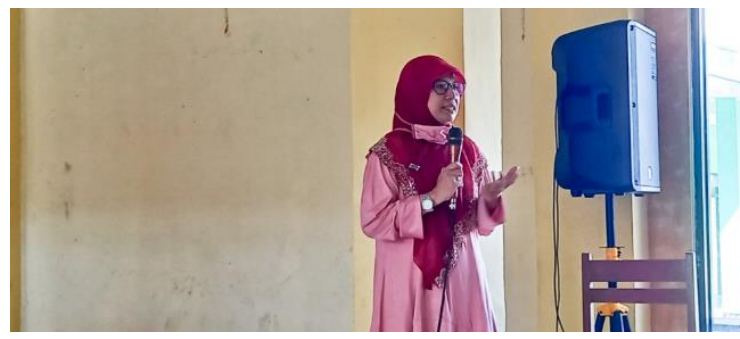

Gambar 4. Pemaparan Materi Computational Thinking

Pemaparan kedua disampaikan oleh Diah Supatmiwati mengenai cara berpikir komputasi yang disisipkan dalam mata pelajaran Bahasa Inggris. Diah memaparkan bahwa CT bisa dipadukan dengan model pembelajaran yang sudah ada.

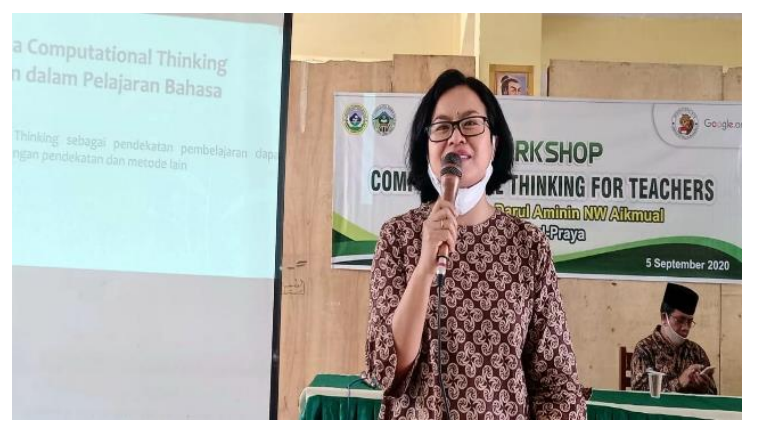

Gambar 5. Pemaparan Materi Computational Thinking dalam Bahasa Inggris https://journal.universitasbumigora.ac.id/index.php/ADMA 
Pemateri ketiga disampaikan oleh Wiya Suktiningsih mengenai cara berpikir komputasi yang disisipkan dalam mata pelajaran Bahasa Indonesia.

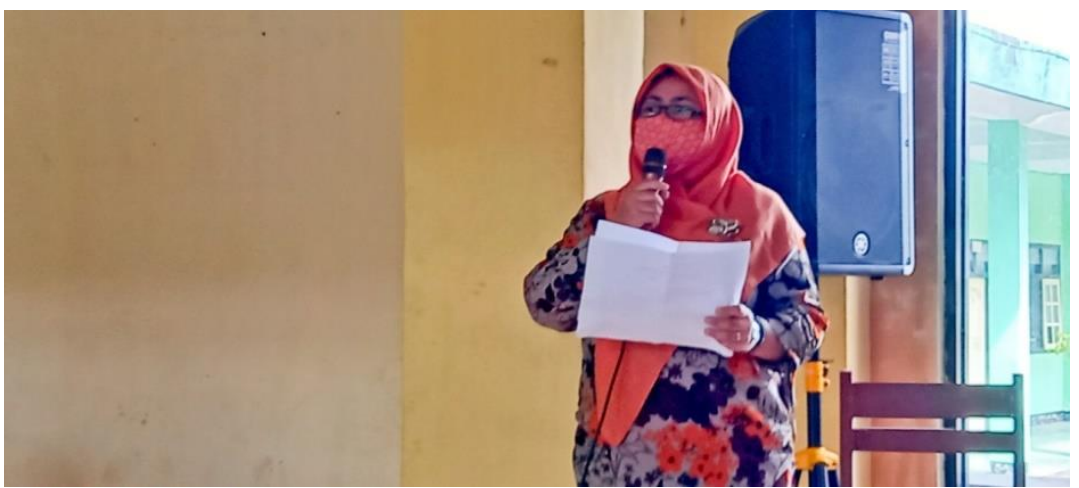

Gambar 6. Pemaparan materi computational thinking dalam Bahasa Indonesia

Setelah pemaparan teori, kegiatan dilanjutkan dengan sesi praktik yaitu pembahasan contoh soal dan analisa 4 metode berpikir komputasi setingkat MI dan Mts. Beberapa contoh soal diambil langsung dari modul yang dikeluarkan oleh kemendikbud. Berikut salah satu contoh soal

(Make story with boxes) This lesson is all about a "Task with simple Instructions." Students will be charged with figuring out how to arrange correct sentences and make a story.
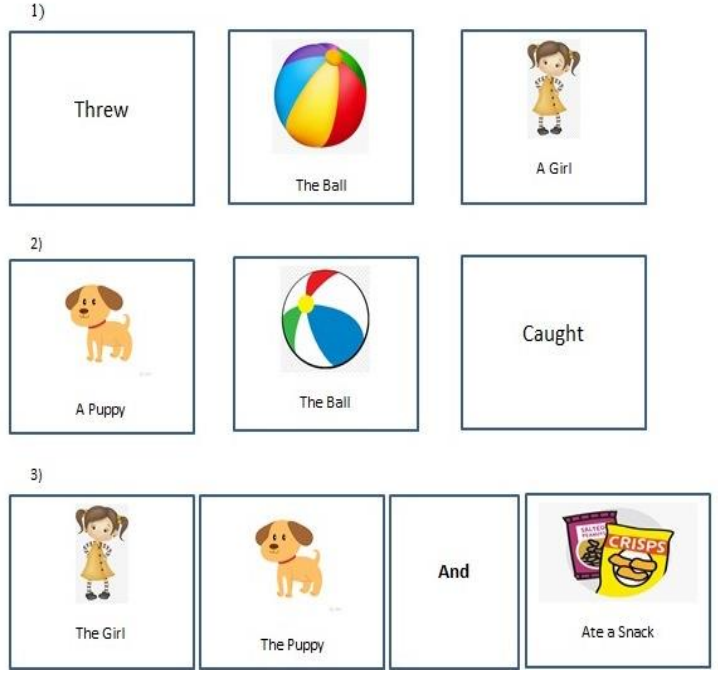

Gambar 7. Contoh soal computational thinking

\section{Analisa Computational Thinking}

1) Abstraksi: mengetahui susunan kalimat sederhana bahasa Inggris

2) Dekomposisi: menyusun kalimat dan cerita berdasarkan dari kotak-kotak tersebut serta mengidentifikasi Subject, verb dan object

3) Pengenalan Pola: menemukan pola kalimat sederhana dalam bahasa inggris

4) Algoritma: menemukan Urutan gramatikal dalam penyusunan kalimat bahasa Inggris. Menentuan urutan peristiwa dan menyusunnya menjadi cerita. 
Para guru sangat antusias dalam mengikuti sesi praktik ini, mahasiswa yang dilibatkan juga sangat membantu dalam berinteraksi dan berdiskusi aktif dengan peserta pengabdian.

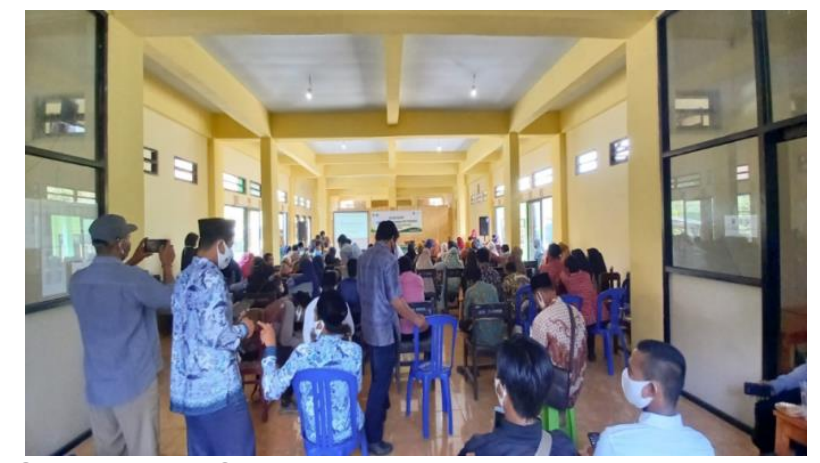

Gambar 8. Sesi praktik dan diskusi pengabdian

Pada sesi terakhir, acara dilanjutkan dengan pengisian kuesioner setelah (pasca) kegiatan. Berbeda dengan kuesioner pra-kegiatan yang bertujuan untuk mengetahui pengetahuan umum peserta, kuesioner pasca-kegiatan ditujukan untuk mendapatkan umpan balik, hasil dan dampak pengabdian, dengan hasil sebagai berikut:

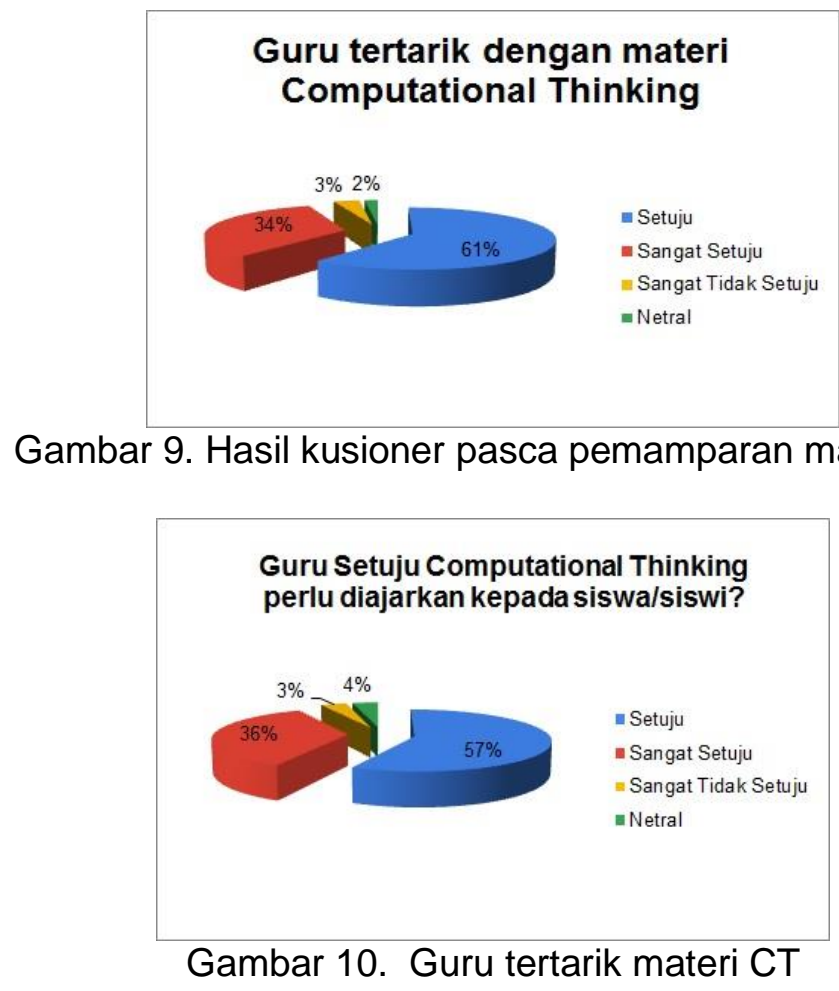

dari 87 guru peserta sosialisasi, 61\% peserta tertarik dengan materi yang dipaparkan dan $36 \%$ sangat setuju dan $57 \%$ setuju cara berpikir komputasi dikenalkan dan diajarkan kepada siswa/siswi. Dari gambar 9 dapat dikesimpulan bahwa mayoritas guru peserta sosialisasi setuju berpikir komputasi wajib dikuasai oleh semua orang, terutama pada era revolusi industri 4.0 sekarang ini. 


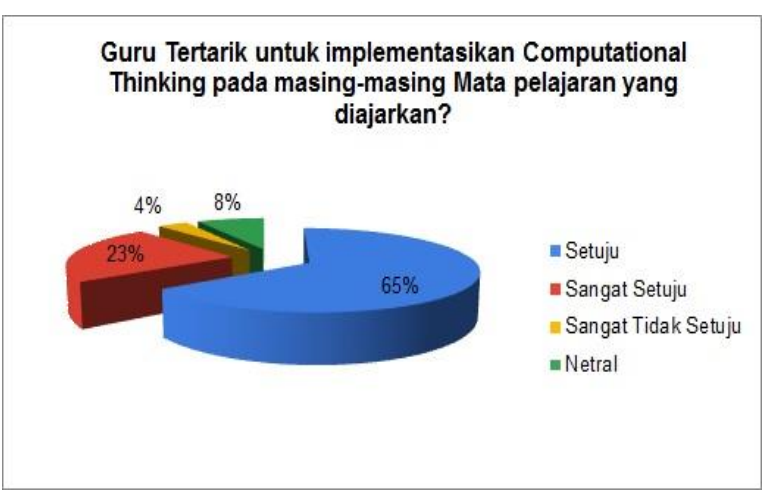

Gambar 11. Guru tertarik implementasi materi CT pada mata pelajaran

Dari gambar 11 bisa dilihat bahwa para guru juga sepakat untuk menyisipkan materi berpikir komputasi ke dalam mata pelajaran yang mereka ampu, walaupun masih ada sekitar $4 \%$ guru yang kurang setuju. Hal ini berkaitan dengan masih bingungnya guru tersebut pada bagian mana yang dapat disisipkan materi berpikir komputasi dan menyarankan ada pengabdian sejenis yang fokus pada implementasi pada pembuatan soal-soal berpikir komputasi.

\section{Kesimpulan}

Dengan terlaksananya pengabdian kepada masyarakat ini, diharapkan guru-guru MI dan MTs swasta di wilayah Lombok Tengah dapat menggunakan dan menyesuaikan materi berpikir komputasi (computational thinking) ke dalam masing-masing mata pelajaran yang mereka ampu. Metode ceramah yang menjelaskan pengertian, kegunaan dan manfaat berpikir komputasi menambah motivasi guru peserta sosialisasi untuk menerapkan computational thinking, dilanjutkan dengan praktik dan diskusi. Pembahasan soal membuat peserta mendapat gambaran lebih utuh mengenai berpikir komputasi. Hasil kuesioner setelah pengabdian didapatkan para guru telah memahami dan mengerti berpikir komputasi merupakan salah satu keahlian utama yang dapat menunjang kemampuan berpikir siswa dalam kehidupan sehari-hari dan sepakat bahwa contoh-contoh soal berpikir komputasi harus mulai ditambahkan dalam materi mata pelajaran.

\section{Ucapan Terimakasih}

Terimakasih kepada Biro Bebras Universitas Bumigora dan Yayasan Islamic Studies Iltihadul Ikhlas Aik Mual, yang telah membantu dan bekerjasama sehingga pelaksanaan program Computational Thinking dapat berjalan dengan lancar. 


\section{Daftar Pustaka}

Bebras. 2017. "Apa Itu Bebras?" Bebras.id: 2-4. https://bebras.or.id/v3/apa-itubebras/\#: :text=Secara harfiah\%2C "Bebras" adalah, dari 55 negara di dunia.

2018. "Tentang Bebras Indonesia Kegiatan Bebras Indonesia." Bebras.id: 4-7. http://bebras.or.id/v3/.

Diy, Kanwil Kemenag. 2021. "Menag Dorong Injeksi Computational Thinking Pada Madrasah." : 1-5.

Kotsopoulos, Donna et al. 2017. "A Pedagogical Framework for Computational Thinking." Digital Experiences in Mathematics Education 3(2): 154-71.

Miranti, Ira, Nurjanah, and Nina Dwiastuty. 2020. Penggunaan Permainan dalam Pengajaran Bahasa Inggris bagi Guru-Guru Madrasah Ibtidaiyah Muta' Alimin Dan Madrasah Ibtidaiyah. Jurnal PKM: Pengabdian kepada Masyarakat 03(03): 273-78. https://journal.Ippmunindra.ac.id/index.php/pkm/article/view/6839.

Rozi, Bahru. 2020. 9 Jurnal Pendidikan Islam Problematika Pendidikan Islam Di Era Revolusi Industri 4.0.

Wing, Jeannette M. 2008. "Computational Thinking and Thinking about Computing." Philosophical Transactions of the Royal Society A: Mathematical, Physical and Engineering Sciences 366(1881): 3717-25.

Yadav, Aman, Hai Hong, and Chris Stephenson. 2016. "Computational Thinking for All: Pedagogical Approaches to Embedding 21st Century Problem Solving in K-12 Classrooms." TechTrends 60(6): 565-68. http://dx.doi.org/10.1007/s11528-016-0087-7. 
